\title{
MSR1 AND CXCL16 SCAVENGER RECEPTORS IN ADIPOSE TISSUE ARE POSITIVELY ASSOCIATED WITH BMI AND INSULIN RESISTANCE
}

C Santiago-Fernández ${ }^{1}$, C Gutiérrez-Repiso², J Alcaide ${ }^{1}$, JM García-Almeida ${ }^{1,3}$, L Ocaña-Wihelmi ${ }^{4}$, A Rodríguez-Morata ${ }^{5}$, FJ Tinahones ${ }^{1,3}$, E García-Fuentes ${ }^{2,3}$, L Garrido-Sánchez ${ }^{1,3}$.

${ }^{1}$ Unidad de Gestión Clínica de Endocrinología y Nutrición, Instituto de Investigación Biomédica de Málaga (IBIMA), Hospital Clínico Virgen de la Victoria, Universidad de Malaga, España. 2 Unidad de Gestión Clínica de

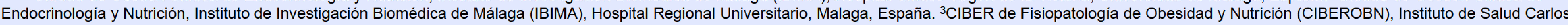

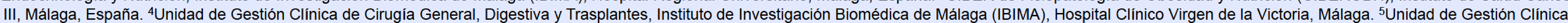
de Angiología y Cirugía Vascular, Instituto de Investigación Biomédica de Málaga (IBIMA), Hospital Clínico Virgen de la Victoria, Málaga.

\section{Background}

Obesity is associated with an increasing risk of diabetes and atherosclerosis. Previous studies in animals show that oxidized low-density lipoprotein (OxLDL) can be captured by the adipocyte through different scavenger receptors (SR) and thus contribute to the worsening of insulin resistance (IR).

\section{Objetive}

To analyze in vivo the association between levels of OxLDL and different SR present in adipose tissue and their relationship with the presence of obesity and inlusin resistance.

\section{Material and Methods}

To study the levels of OxLDL and different $S R$ in serum as well as the levels of gene expression of the lectin-like oxLDL1 (LOX-1), macrophage scavenger receptor 1 (MSR1) and chemokine (C-X-C motif) ligand 16 (CXCL16) SR in visceral adipose tissue (VAT) and subcutaneous (SAT) in 21 normal weight patients and 26 morbid obesity patients (MO) depending on their IR.

\section{Results}

Table 1 summarizes the biochemical and anthropometric characteristics in the non-obese and morbidly obese subjects classified according to their insulin resistance. In table 2 we can observe the levels of cytokines and scavenger receptor in serum in all the subjects. LOX-1, MSR-1 and CXCL16 SR are more expressed in MO patients (Figure 1, 2 and 3). MSR1 and CXCL16 SR in VAT and SAT are positively associated with BMI, the circumference of waist and hips, insulin, glucose, HOMA-IR and triglycerides, and negatively associated with adiponectin and HDL-c. LOX-1 SR in VAT is positively associated with BMI, circumference of waist and hips and negatively with adiponectin and HDL-C.

Table 1. Anthropometric and biochemical variables in the non-obese and morbidly obese subjects classified according to their insulin resistance.

\begin{tabular}{|c|c|c|c|}
\hline & $\begin{array}{c}N W \\
(n=21)\end{array}$ & $\begin{array}{c}\text { MO-L-IR } \\
(n=13)\end{array}$ & $\begin{array}{c}\text { MO-H-IR } \\
(n=13)\end{array}$ \\
\hline Sex (male/female) & $9 / 12$ & $4 / 9$ & $5 / 8$ \\
\hline Age (years) & $44.67 \pm 16.10$ & $40.80 \pm 11.76$ & $37.50 \pm 10.19$ \\
\hline BMI $\left(\mathrm{Kg} / \mathrm{m}^{2}\right)$ & $22.52 \pm 1.74^{c}$ & $52.32 \pm 8.53^{\mathrm{b}}$ & $58.38 \pm 7.60^{\mathrm{a}}$ \\
\hline Waist (cm) & $82.17 \pm 9.44^{\mathrm{c}}$ & $133.73 \pm 15.20^{\mathrm{b}}$ & $149.50 \pm 16.39^{\mathrm{a}}$ \\
\hline Hip (cm) & $96.57 \pm 5.49^{\mathrm{b}}$ & $151.09 \pm 15.71^{a}$ & $159.75 \pm 13.38^{\mathrm{a}}$ \\
\hline Glucose (mg/dL) & $89.48 \pm 14.03^{c}$ & $87.23 \pm 9.67^{a, b}$ & $101.00 \pm 9.63^{a}$ \\
\hline Cholesterol (mg/dL) & $202.86 \pm 34.44^{\mathrm{a}}$ & $205.00 \pm 44.93^{\mathrm{a}}$ & $185.46 \pm 37.58^{b}$ \\
\hline Triglycerides (mg/dL) & $124.10 \pm 100.27$ & $107.91 \pm 55.61$ & $165.31 \pm 89.23$ \\
\hline HDL-c (mg/dL) & $55.81 \pm 13.54^{\mathrm{a}}$ & $44.90 \pm 11.79^{b}$ & $42.38 \pm 10.72^{b}$ \\
\hline LDL-c (mg/dL) & $121.47 \pm 26.91$ & $131.54 \pm 30.59$ & $116.16 \pm 28.62$ \\
\hline Insulin $(\mu \mathrm{IU} / \mathrm{mL})$ & $13.56 \pm 9.56^{\mathrm{b}}$ & $11.41 \pm 4.56^{\mathrm{b}}$ & $34.99 \pm 9.78^{\mathrm{a}}$ \\
\hline HOMA-IR & $3.00 \pm 2.15^{b}$ & $2.42 \pm 0.85^{b}$ & $8.59 \pm 2.00^{\mathrm{a}}$ \\
\hline
\end{tabular}

The results are given as the mean \pm standard deviation. MO: Morbid Obesity patients; IR: insulin resistance; BMI: body mass index; HOMA-IR: meassur of the index of insulin resistace. Different letters show significant differences among the measure of the different groups $(p<0.05)$

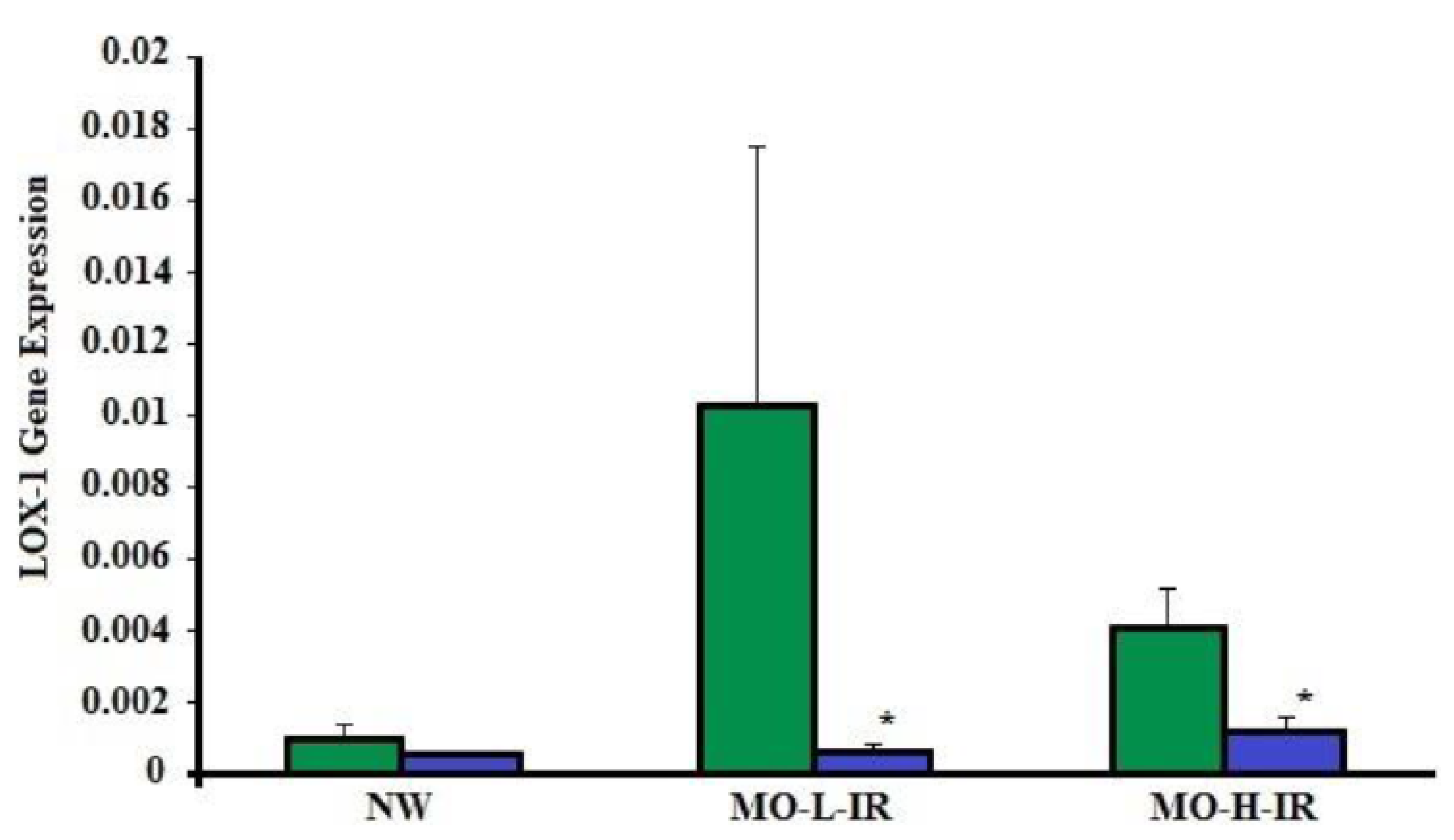

Figure 1. mRNA expression of oxidized low density lipoprotein (lectin-like) receptor 1 (LOX-1) in human visceral (VAT) ( $\square$ ) and subcutaneous adipose tissue (SAT) ( $\square$ ) in the non-obese and morbidly obese subjects classified according to their insulin resistance. The results are given as the mean \pm SEM. *Differences between visceral and subcutaneous tissue $(p<0.05)$

Table 2. Citokines and scavenger receptors variables in serum in the non-obese and morbidly obese subjects classified according to their insulin resistance.

\begin{tabular}{|l|c|c|c|}
\cline { 2 - 4 } \multicolumn{1}{c|}{} & NW & MO-L-IR & MO-H-IR \\
\hline Leptin & $14.85 \pm 15.58^{\mathrm{b}}$ & $77.22 \pm 45.54^{\mathrm{a}}$ & $61.36 \pm 22.433^{\mathrm{a}}$ \\
\hline Adiponectin & $25.41 \pm 16.04^{\mathrm{a}}$ & $11.74 \pm 3.55^{\mathrm{b}}$ & $7.85 \pm 4.50^{\mathrm{b}}$ \\
\hline Oxidized LDL & $49446.18 \pm 8869.78$ & $57391022 \pm 18721080$ & $75598.53 \pm 26506.60$ \\
\hline CXCL16 & $5224.75 \pm 1229.51$ & $6505.50 \pm 3375.21$ & $7338.21 \pm 1817.69$ \\
\hline LOX-1 & $32.00 \pm 23.01^{\mathrm{b}}$ & $40.97 \pm 20.80^{\mathrm{a}, \mathrm{b}}$ & $65.28 \pm 43.63^{\mathrm{a}}$ \\
\hline MSR1 & $24.67 \pm 4.07^{\mathrm{b}}$ & $34.56 \pm 8.97^{\mathrm{a}}$ & $32.87 \pm 10.15^{\mathrm{a}}$ \\
\hline
\end{tabular}

The results are given as the mean \pm standard deviation. Different letters show significant differences among the measure of the different groups $(p<0.05)$.
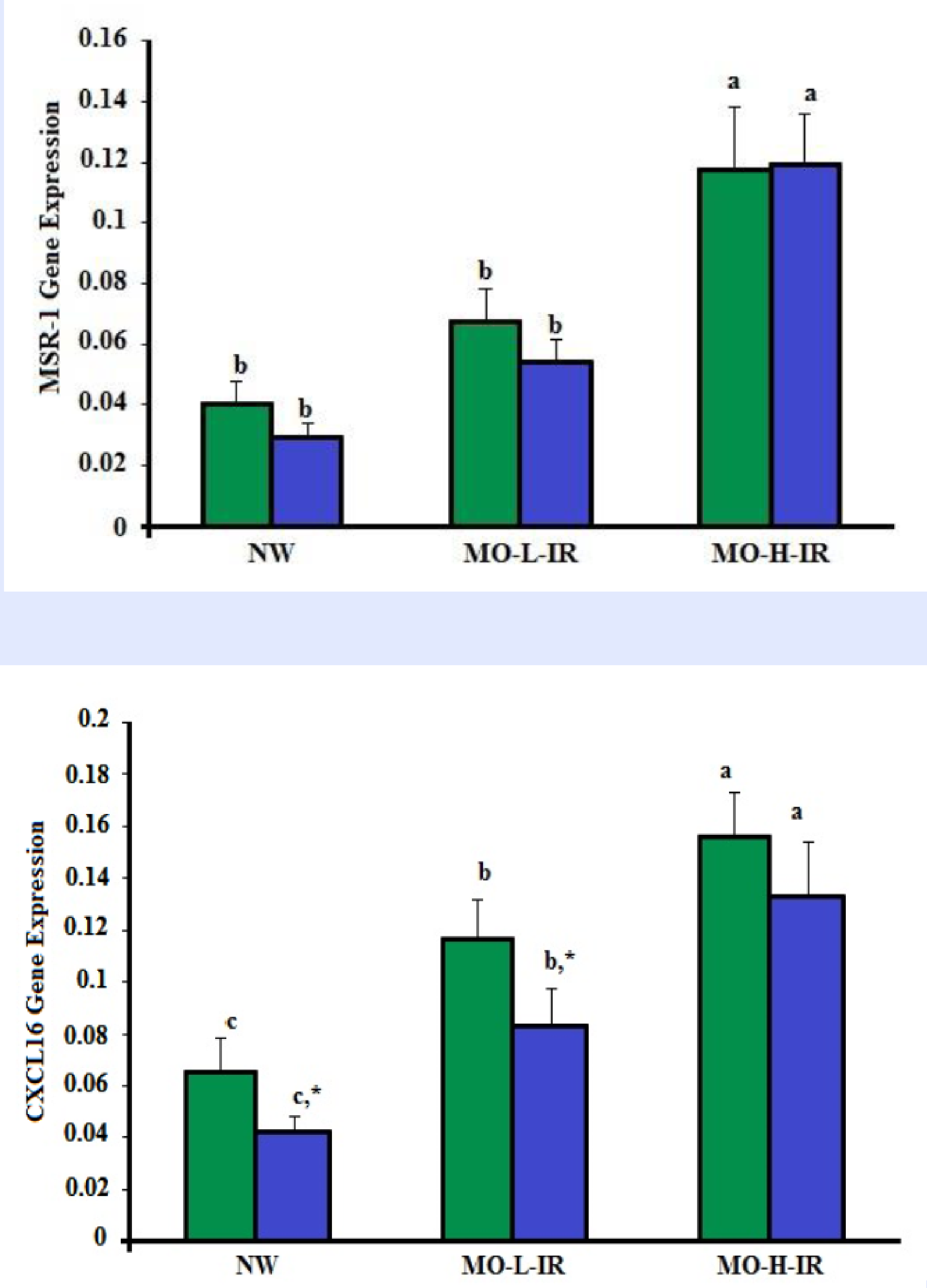

Figure 2. mRNA expression of MSR1 in human visceral (VAT) (E) and subcutaneous adipose tissue (SAT) $(\square)$ in the non-obese and morbidly obese subjects classified according to their insulin resistance. The results are given as the mean \pm SEM. Differents letters show significant differneces among the measure of the different groups $(p<0.05)$.

\section{Conclusions}

In this research we demonstrate for the first time the positive association between the levels of gene expression of MSR1 and CXCL16 SR with the BMI and the IR in the adipose tissue.

\section{Acknowledgments}

This manuscript was supported by grants from the Instituto Salud Carlos III (CP13/00188), Spain CIBERObn is an initiative of ISCIII. L. Garrido-Sánchez is supported by a fellowship from the Fondo de Investigación Sanitaria (FIS) "Miguel Servet I" MS13/00188-CP13/00188. This study has been co-funded by FEDER funds.
Figure 3. mRNA expression of CXCL16 in human visceral (VAT) (घ) and subcutaneous adipose tissue (SAT) ( $\square$ ) in the non-obese and morbidly obese subjects classified according to their insulin resistance. The results are given as the mean \pm SEM. Differents letters show significant differneces among the measure of the different groups $(p<0.05)$ 